\title{
USING INSTAGRAM IN THE PROCESS OF LEARNING ENGLISH LANGUAGE
}

\author{
Dinara Sergaliyeva ${ }^{1}$, Dariya Assanova ${ }^{2}$ \\ ${ }^{1}$ E.A. Buketov Karaganda University, Karaganda, Kazakhstan \\ ${ }^{2}$ E.A. Buketov Karaganda University, Karaganda, Kazakhstan \\ ORCID ID: 0000-0002-4624-7012
}

\begin{abstract}
Currently, social networks are increasingly attracting the sphere of education. The options for using Instagram in teaching are versatile and often depend on the imagination and creativity of the teacher. In this article, the authors consider the theoretical foundations of using the Instagram social network in teaching English. Special attention is paid to the definition of Instagram, the description of its capabilities in the educational environment. Students were experimentally tested to identify the effectiveness of using the Instagram service. Based on this study, the authors concluded that the joint use of traditional teaching methods with the Instagram Internet resource led to a stronger fixation of the material than using only traditional methods.
\end{abstract}

\section{INTRODUCTION}

The Internet is becoming a platform for barrier-free communication of people from different cities, countries, and cultures. Social networks today have become one of the most important, convenient and effective means of communication between people. The goal of social media is to make the world more open [Arsova, 2021; Sushchenko, Akhmedova, Stryzhak, 2021].

Today, social networks have a great impact on many areas of our lives, in particular on education, changing the educational paradigm as a whole. Global network - an opportunity to form an individual educational trajectory [Feshchenko, 2019]. For this reason, professional network communities are becoming an effective tool in modern pedagogy in the field of education. Network support opens up new opportunities for organizing broad professional interaction, sharing knowledge and experience, improving professional skills and attracting new members of the community.

The introduction of professional social networks in teaching activities allows us to achieve the formation of a unified information space of the education system; the creation of high-quality, open and accessible portals of educational resources; the formation of a new culture of thinking of participants in the educational process.

The relevance of this work is dictated by the digitalization of educational processes. Internet technologies and social networks are increasingly becoming part of pedagogical methods and approaches. However, the effectiveness or ineffectiveness of these new tools in educational processes is still poorly understood and does not have a broad information base. Therefore, the study of Instagram as a tool of pedagogical activity is relevant both for the theoretical understanding of modern educational processes, and for solving practical problems of education and teaching English.

Researchers note that Web 2.0 technologies, which include social networks, provide ample opportunities for intensifying and individualizing the educational process, including teaching foreign languages.

The undeniable advantage of social networks is that they are a free resource. Often, educational institutions cannot afford the purchase of expensive software for organizing the information environment. In this case, social networks would become an indispensable assistant in organizing interactive virtual interaction between teachers and students.

The use of social networks, in particular the Instagram application, in the educational process promotes the exchange of information, increases the motivation of students, stimulates the development of creative abilities and cognitive interest. All these factors have a positive impact on the formation of knowledge and skills. 


\section{MAIN PART}

Instagram today is one of the social networks that have gained particular popularity among today's youth. This is an application for sharing photos and videos with social network elements, allowing you to take photos and videos, apply filters to them, and distribute them through your service and a number of other social networks [Kolesnikova, 2019].

Instagram was developed in San Francisco by Kevin Systrom, and Mike Krieger. The app appeared in the Apple App Store in October 2010. In January 2011, hashtags were added to the app to make it easier to find users and photos. In 2012, Facebook announced its purchase of the mobile photo app Instagram for $\$ 1$ billion. By December 2010, Instagram had one million registered users. In June 2011, it was already five million. By September, this number had doubled, and by March 2012, the number of users had reached almost 30 million. By the end of February 2013, Instagram had announced 100 million active users. And at the end of March 2014, Mark Zuckerberg announced the registration of the 200-millionth user [Vlastna, 2018A].

Instagram is the second most downloaded free app in the Apple app store. The social network is in the top 10 most popular search queries in Google. Instagram is most popular in the United States (110 million), Brazil (70 million), India (69 million), Indonesia (59 million) and Russia (40 million) [https://instaguru.online/]. The data is shown in Figure 1.

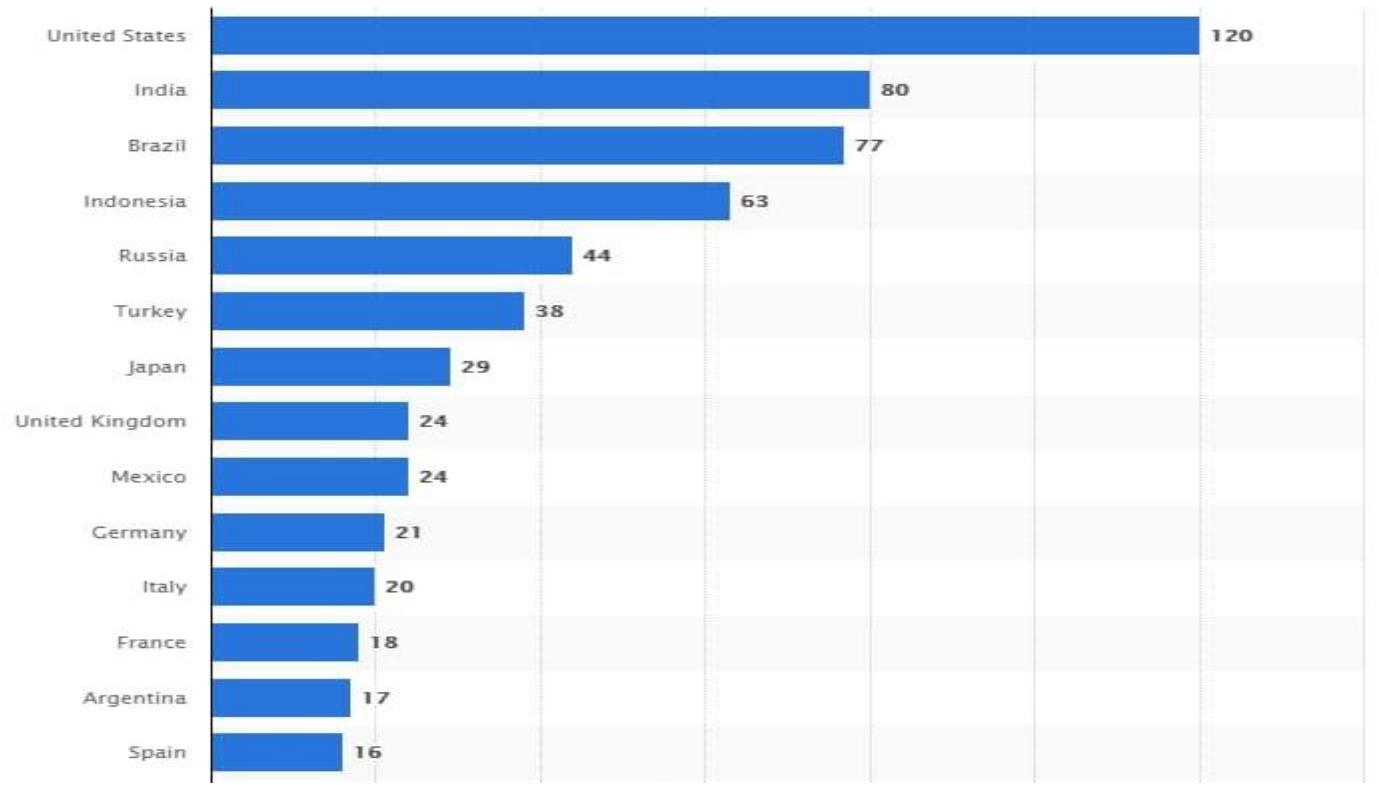

Figure 1. Leading countries by the number of Instagram users as of January 2020.

Instagram is very famous for its hashtags. These are clickable placemarks consisting of words, numbers, emojis, or underscores. They help you divide the content that users post into categories. For example, you can find recipes on one hashtag on Instagram, English lessons on others, funny videos with children on others, etc. If you click on the hashtag \#wildlife in a National Geographic post, you'll see other posts dedicated to wild animals. The Later service together with the Fohr platform analyzed trends in the behavior of influencers, user data and thousands of Instagram posts. As a result, we found that publications with hashtags attract more reactions. Instagram is changing, but hashtags are still the main tool of movement on the platform [https://rusability.ru/home]. The results of the study are shown in Figure 2. 


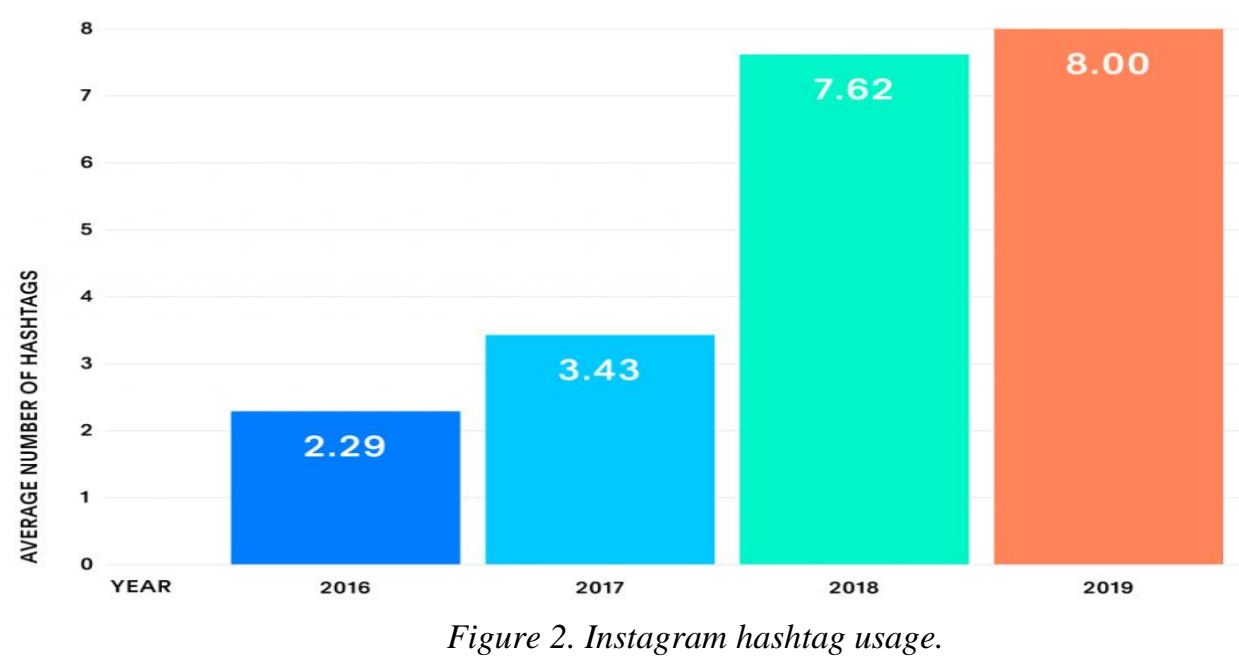

To improve the effectiveness of education, we need alternative methods that would allow students to develop the necessary knowledge, skills and abilities for successful communication, professional and educational activities in the modern high-tech information-intensive world. To achieve this goal, it will be possible to integrate modern multimedia and digital technologies into the process of teaching a foreign language, which can be effectively used in foreign language lessons.

The world is evolving very quickly from a technical point of view. We observe a tendency that students are more interested in viewing photos, videos, or stories on Instagram than sitting in an English class, for example. Since this service arouses students' interest in this way, it should be used to strengthen their own interest and motivate students to learn English.

To analyze the methods of working with the Instagram application and identify the effectiveness of this method, we experimentally tested 30 first-and second-year students. When developing tasks, the individual characteristics and needs of students were necessarily considered.

Instagram is primarily associated with beautiful photos, so students were asked to post a photo on their homepage and describe it using Present Simple and Present Continuous Tenses.

Next, we used comments, the teacher posted a video on his homepage, starting a certain story, and the task of the students was to continue this story with two sentences one by one in the comments to the post.

And with the help of hashtags, the search for the necessary photos was carried out. For example, 5.1 million posts were found on the topic "Hotels" on Instagram. The students described the photos they liked. For example, Sydney's Iconic Hotel, Hotel Koral Beach, Playa del Cura and others. Photos and videos of world-famous hotels interested the students so much that they then went to the page of these hotels and studied their history, the number of visitors, the territory, the advantages, etc.

Also, with the help of "stories" in the Instagram application, the teacher published sentences with and without errors, to which the students answered "right", "wrong". For example, the largest hotel in the world is the Izmailovo Hotel in Moscow, which has 7,500 hotel rooms - "right" and "wrong". Or if grammar or vocabulary was studied, the emphasis was placed on the tenses of verbs or a selection of synonyms, antonyms, etc. The standard version of checking comprehensionquestions with multiple answers were also used.

Finally, the students were divided into small groups and given the task to blog on regular basis their own "instablog" and keep it in English. In order to generalize their knowledge, they posted photos and videos on their blogs, described them, commented on each other's publications, put hashtags, and published stories with interesting facts and stories. Thus, all the students thought and practiced speaking in English.

The holistic implementation of the educational process involves its completion, the achievement of planned and projected results, as well as receiving feedback confirming its 
effectiveness. A necessary condition for evaluating the effectiveness of training is the diagnosis of its results.

Based on the results of the methodology using Instagram, an anonymous test was conducted, which consisted of 5 questions. The responses were graded on a scale from 1 to 10 points. Questions:

1) Are you interested in this method of learning English on the Instagram platform?

2) Have you got the new material?

3) Would you like this technique to be used regularly?

4) Have you improved your knowledge with this method?

5) Will you learn English using Instagram in your free time on your own (marathons, blogs, bloggers, etc.)?

The totals were calculated using the average formula. According to the results of the survey of 30 respondents, the following data were revealed (The results of the survey are shown in Figure 3):

1) Average score 9.5.

2) Average score 9.2.

3) Average score 8.2.

4) Average score 9.5.

5) Average score 9.8 .

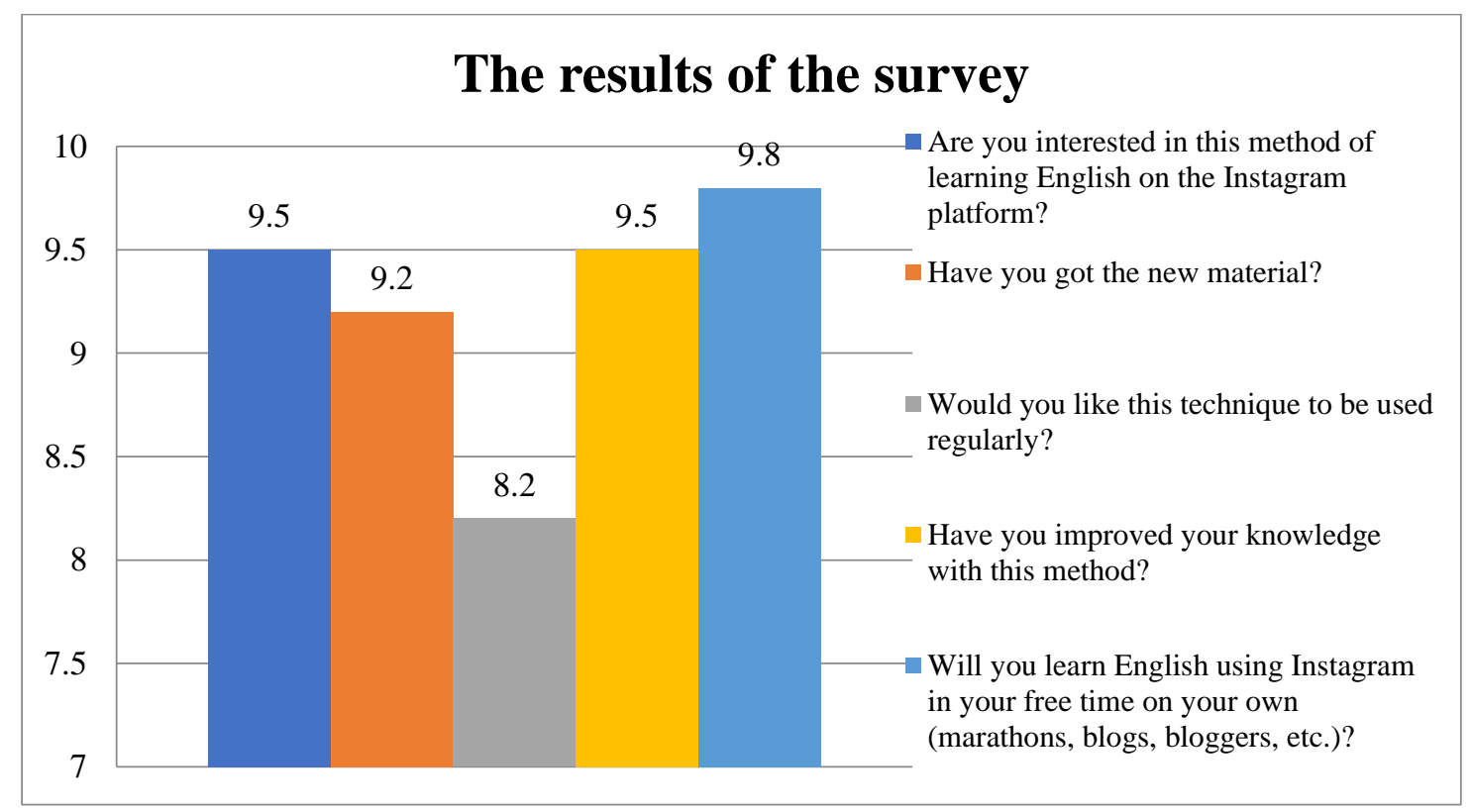

Figure 3. The results of the survey.

We see that the combined use of traditional teaching methods with the online resource Instagram has led to strengthening of teaching materials than using only traditional methods. Live and constant revision of educational material via Instagram has helped students incorporate grammatical units into everyday language usage, making them a real way of communication.

\section{CONCLUSIONS}

The integration of the social network Instagram into the student learning process has shown that learning English using non-specialized social networks provides both the teacher and the students with a number of advantages over traditional methods of interaction. In particular, the positive aspects of using Instagram for educational purposes include:

- A comfortable and familiar environment for students.

- A wide range of opportunities and forms of interaction, a variety of forms of communication.

- Unique identification of users. 
- The ability to filter incoming information.

- Ample opportunities for joint activities.

- The possibility of organizing continuous learning [Vlaskina, 2018B].

Thus, it should be noted that at the present stage of development of the methodology of teaching foreign languages, there is a tendency towards a transition from a communicative approach to its variety - an interactive approach, which includes active interaction of all students of the group, in the process of which there is a mutually enriching exchange of authentic personally significant information in a foreign language and at the same time, interpersonal communication skills are acquired. All of this is possible especially on social networks. Since, it is a powerful and effective tool that has a wide range of opportunities and unique positive features, the potential of which must be used in modern education.

As one of the social media platforms, Instagram has become widely used by students. It provides users with an instant way to capture and share their life moments with friends through a series of (with filters) photos and videos. Students usually have an account on their Instagram and mark every moment of their lives on it, for example by sharing photos and videos. Their subscribers have the opportunity to express their approval, as well as comment on the uploaded picture or video. This communication resource makes Instagram a great tool for learning English. Thus, social networks, in particular Instagram, have ample opportunities to be used in the process of language learning.

\section{REFERENCE:}

Arsova, D. (2021). Skills and competencies of the new generation of students to work with digital devices // "Innovations in technology and education": proceedings of XIV International scientific conference "Innovations in technology and education", 26 march 2021 г.: Kuzbass State Technical University, Belovo, Russia; 2021. - vol. 3., pp. 59-66 (in BG)

Feshchenko A.V., (2019) Social'nye seti v obrazovanii: analiz opyta i perspektivy razvitija [Social networks in education: analysis of experience and development prospects]. Otkrytoe i distancionnoe obrazovanie - Open and distance education. №3, pp. 44-50 [in Russian]

Kolesnikova E.V., (2019) «Instagram» kak interaktivnyj resurs obuchenija inostrannomu jazyku ["Instagram" as an interactive resource for teaching a foreign language']. Voprosy pedagogiki Questions of pedagogy. №12(1), p. 14 [in Russian]

Sushchenko, O., Akhmedova, O., Stryzhak, O. (2021). The use of interactive training technologies in teaching academic disciplines for students of tourism specialities. Access to science, business, innovation in digital economy, ACCESS Press, 2(1): 28-39. https://doi.org/10.46656/access.2021.2.1(3)

Vlastna V.Yu., (2018), Obrazovatel'nyj potencial social'nyh setej «Tvitter» i «Instagram» v obuchenii inostrannym jazykam [Educational potential of social networks "Twitter" and "Instagram" in teaching foreign languages]. Mezhdunarodnyj studencheskij nauchnyj vestnik - International student scientific herald. №1, pp. 1-6 [in Russian]

Vlaskina V.Yu. (2018), Obrazovatel"nyj potencial social"nyh setej Tvitter i Instagram v obuchenii inostrannym jazykam: metodika issledovanija [Educational potential of social networks Twitter and Instagram in teaching foreign languages: research methodology]. Mezhdunarodnyj studencheskij nauchnyj vestnik - International student scientific herald. №5 [in Russian]

https://instaguru.online/

https://rusability.ru/home 